\title{
AVANÇOS NA REGULAMENTAÇÃO DA POLÍTICA DE ESPORTE E LAZER PARA AS PESSOAS COM DEFICIÊNCIA
}

Recebido em: $28 / 12 / 2020$

Aprovado em: 30/01/2021

Licença:@) (1) @

\author{
Débora da Silva Oliveira ${ }^{1}$ \\ Luciana Assis Costa ${ }^{2}$ \\ Universidade Federal de Minas Gerais - UFMG \\ Belo Horizonte - Minas Gerais - Brasil
}

RESUMO: O estudo realizou a análise da regulamentação federal e do município de Belo Horizonte - MG que tem orientado as políticas de esporte e lazer para as pessoas com deficiência. Analisaram-se cinquenta e quatro legislações municipais e outras cinquenta e duas legislações federais e partes da Constituição Federal. Como critério de inclusão adotou-se a presença dos termos: acessibilidade, cultura, turismo, lazer, ócio, recreação, brinquedos, parques, desporto, esporte, pessoa com deficiência, inclusão e inclusão social. Os dados foram analisados seguindo os pressupostos da análise de conteúdo. Os resultados demonstram que avanços nas legislações federais e municipais para as pessoas com deficiência têm induzido a formulação de políticas de esporte e lazer inclusivas. Também sinalizam para a necessidade de detalhamento das atribuições e responsabilidades dos entes federados para a implementação da política.

PALAVRAS-CHAVE: Políticas Públicas. Pessoa com Deficiência. Legislação.

\section{ADVANCES IN SPORT AND LEISURE POLICY REGULATIONS FOR PEOPLE WITH DESABILITIES}

ABSTRACT: The study carried out an analysis of the federal and municipal regulations of Belo Horizonte-MG, which has guided sports and leisure policies for people with disabilities. Fifty-four municipal legislations and fifty-two other federal legislations and parts of the Federal Constitution were analyzed. As an inclusion criterion, the following terms were adopted: accessibility, culture, tourism, leisure, leisure, recreation, toys,

\footnotetext{
${ }^{1}$ Mestra em Estudos do Lazer pelo Programa de Pós-graduação Interdisciplinar em Estudos do Lazer (PPGIEL) da Universidade Federal de Minas Gerais (UFMG), Licenciatura em Educação Física pela UFMG, Professora efetiva na Prefeitura Municipal de Santa Luzia/MG, Integrante do Grupo de Pesquisa em Políticas Públicas de Esporte e Lazer (POLIS-UFMG).

2 Professora do Departamento de Terapia Ocupacional da Universidade Federal de Minas Gerais (UFMG), Coordenadora do Grupo de Pesquisa em Políticas Públicas de Esporte e Lazer (POLIS-UFMG), Docente permanente no Programa de Pós-graduação Interdisciplinar em Estudos do Lazer (PPGIEL) UFMG e ao Programa de Pós-Graduação em estudos da Ocupação - UFMG.
} 
parks, sports, sports, people with disabilities, inclusion and social inclusion. The data were analyzed following the assumptions of the content analysis. The results show that advances in federal and municipal legislation for people with disabilities have led to the formulation of inclusive sports and leisure policies. They also signal the need to detail the attributions and responsibilities of the federated entities for the implementation of the policy.

KEYWORDS: Public Policies. People with Disabilities. Legislation.

\section{Introdução}

A Constituição Federal de 1988 inaugura um desenho amplificado de proteção social, com o reconhecimento legal de uma gama de direitos sociais, dentre eles, o esporte e o lazer (SANTOS, 2014). Também reitera elementos societários fundantes para a democracia, como o bem-estar de todas as pessoas, sem discriminação e preconceitos de quaisquer origens. De acordo com a constituição, o Estado deverá "promover o bem de todos, sem preconceitos de origem, raça, sexo, cor, idade e quaisquer outras formas de discriminação" (BRASIL, 1988). E ainda destaca "a proteção e integração social das pessoas portadoras de deficiência" (BRASIL, 1988). Ou seja, o direito ao lazer passa a ser lido como elemento de promoção e integração social de todos, sobretudo das pessoas com deficiência.

Desde 1988, normas constitucionais, leis complementares, portarias e decretos foram promulgados, buscando regulamentar e até mesmo complementar a Constituição. Neste contexto, diversas políticas setoriais foram formuladas para atender as especificidades de grupos, no sentido da ampliação equânime dos direitos sociais. No que se trata do direito ao lazer, essa ampliação ocorreu a partir da década de 1990, quando algumas políticas inclusivas se destacaram, como o Estatuto da Criança e do Adolescente - ECA (BRASIL, 1990), a Política Nacional do Idoso (BRASIL, 1994) e a Política Nacional da Pessoa Portadora de Deficiência (BRASIL, 1999), que passaram a contemplar o lazer, visando ao acesso desse direito a todos e todas. 
Não obstante a atuação e pressão política dos movimentos sociais em defesa da igualdade de direitos para as pessoas com deficiência no Brasil e no mundo e dos avanços legais em prol desses direitos, é perceptível que o Estado ainda não assegura os direitos das pessoas com deficiência de modo igualitário e universal (CARAVAGE e OLIVER, 2018; ARAUJO et al., 2017; ANDRADE e ALMEIDA, 2012).

Neste estudo, ressaltaremos como a regulamentação do direito ao esporte e ao lazer para a pessoa com deficiência tem sido construída, considerando que a Política Nacional da Pessoa Portadora de Deficiência, que passa a vigorar no final da década de 1980 e tem sua expansão nos anos 2000, defende o direito desses sujeitos à participação na vida cultural, em igualdade de oportunidades com as demais pessoas (BRASIL, 2009b).

Pesquisa realizada por Barbosa, Rezende e Brito (2020) demonstra produção escassa de estudos nacionais com foco no esporte e no lazer das pessoas com deficiência (CARAVAGE e OLIVER, 2018). Ainda segundo Barbosa, reiterando essa afirmativa, a partir de uma revisão de literatura em periódicos da área de lazer entre 1998 e 2019, foram identificados apenas dez estudos sobre o lazer da pessoa com deficiência, o que demonstra a escassez de pesquisas nessa área.

Quanto aos estudos existentes, Andrade e Almeida (2012) salientam que nos últimos anos tem-se percebido evolução crescente nas legislações sobre pessoas com deficiência. Ainda baseado no marco regulatório da área, Andrade e Almeida salientam que a "Convenção sobre os Direitos das Pessoas com Deficiência e a Política Nacional de Esporte deixam claro que todas as pessoas têm direito de participar em igualdade de condições" (ANDRADE e ALMEIDA, 2012, p. 57). Não obstante os avanços nas regulamentações, a inclusão de temas pertinentes às pessoas com deficiência na área do esporte e lazer, tem sido encampado pela Política Nacional do Esporte e pelo Caderno 
Legado Social - Rio 2016, que possuem pontos específicos capazes de promover a inclusão social. Todavia os autores destacam a ausência de detalhamento das ações que devem ser realizadas para a implementação dessas políticas (ANDRADE e ALMEIDA, 2012).

Caravage e Oliver (2018) em estudo realizado em uma cidade de grande porte no estado de São Paulo demonstraram que a realização de megaeventos nos últimos anos no Brasil trouxe avanços legislativos, de infraestrutura esportiva, pesquisas e capacitação profissional destinada às pessoas com deficiência. Vale ressaltar que a política da pessoa com deficiência é resultado de um conjunto de decisões pactuadas entre governos e a sociedade civil, que objetiva a garantia da inclusão social (SILVA; MENDONÇA; SAMPAIO, 2014).

A partir do exposto, o estudo centrou-se na análise da regulamentação federal e do município de Belo Horizonte - MG que tem orientado as políticas de esporte e lazer para as pessoas com deficiência. O artigo está dividido em três seções, sendo a primeira referente à inclusão do direito da pessoa com deficiência na política nacional de esporte e lazer; a segunda trata dos direitos ao esporte e lazer das pessoas com deficiência e a terceira aborda as regulamentações municipais que contemplam a inclusão das pessoas com deficiência na política de esporte e lazer de Belo Horizonte.

\section{Metodologia}

O presente estudo configura-se como uma pesquisa qualitativa descritiva de natureza documental. Como técnica de coleta de dados foi utilizada a análise documental de fontes primárias e secundárias, de caráter público e que, preferivelmente, estivessem disponíveis em plataformas oficiais, assim como documentos 
disponibilizados pela Secretaria Municipal de Esportes e Lazer da Prefeitura Municipal de Belo Horizonte - MG, conforme orientado por May (1993).

Foram realizadas as análises de leis e decretos do município de Belo Horizonte MG e do Governo Federal que regulamentam o acesso ao esporte e ao lazer para as pessoas com deficiência. Dessa forma, foram analisadas quarenta e quatro (44) leis municipais, quarenta e duas (42) leis federais, dez (10) decretos municipais, dez (10) decretos federais e partes da Constituição Federal de 1988 que dispõem sobre o esporte e/ou lazer como direito social. Para acessar as leis e os decretos, foram utilizados o Portal de leis Municipais e o site oficial do Planalto e da Casa Civil do Brasil, ambas as plataformas de arquivamento e transparência que permitem o acesso ao arcabouço normativo brasileiro.

O critério de inclusão para seleção e análise das legislações e decretos federais e municipais foi a presença dos seguintes termos, no conteúdo dos documentos: acessibilidade, cultura, turismo, lazer, ócio, recreação, brinquedos, parques, desporto, esporte, pessoa com deficiência, inclusão e inclusão social.

Assim, após a exclusão das leis e decretos que não continham conteúdo relevante ao estudo, os documentos incluídos foram devidamente catalogados, a fim de formar o banco de dados. Para a formulação do banco de dados acerca do arcabouço normativo, foram catalogadas as datas de proposição, datas de promulgação, tema central tratado no documento, bem como trechos e conteúdos específicos sobre o objeto de estudo desta pesquisa. Assim, após a formatação do banco de dados, organizou-se uma linha do tempo do arcabouço legal.

Durante e após as coletas dos dados por meio dos documentos adotou-se a análise de conteúdo. Bardin (1979) descreve a análise de conteúdo com uma técnica que utiliza procedimentos sistemáticos para a descrição de uma mensagem. Similar à análise 
documental, a análise de conteúdo busca, a partir da descrição da comunicação, realizar inferências relacionadas ao tema ao qual se dedica a mensagem.

Por ser uma pesquisa documental, o estudo se eximiu da apreciação no comitê de ética.

\section{O Arcabouço Legal que Regulamenta a Política de Esporte e Lazer para as Pessoas com Deficiência}

O arcabouço normativo constitui uma das dimensões de análise de política pública que remete a institucionalidade da política, apesar de a presença de leis e regulamentos não garantirem, a priori, a execução da política (NOYA e GOMES, 2019).

Nessa seção são abordadas temáticas que abrangem as políticas de esporte e o lazer considerando seu aspecto normativo. Para isso, é apresentada a legislação que tem como objetivo orientar programas, projetos e ações de esporte e lazer, com destaque para a regulamentação das ações de esporte e/ou lazer para pessoas com deficiência na esfera federal e no município de Belo Horizonte.

Foi traçada uma linha histórica de como foram e estão sendo orientadas as políticas de esporte e lazer que atendem as pessoas com deficiência no Brasil, com ênfase no município de Belo Horizonte. Na organização dessa linha, foram utilizados documentos disponibilizados nas plataformas do governo federal, bem como do município estudado.

O recorte se deu a partir de documentos promulgados que tratam de diretrizes e regras para a implementação, manutenção e acesso a políticas específicas e não específicas de lazer. Ademais, foram selecionados documentos que faziam referência aos seguintes termos: lazer, esporte, diversão, tempo livre, ócio, política publica, 
inclusão e inclusão social; além de termos relacionados a equipamentos específicos de lazer, como parques, brinquedos, cinemas e teatros.

Para a organização desse conjunto de leis, inicialmente, reportou-se ao portal oficial da Secretaria Nacional de Esporte, Educação, Lazer e Inclusão Social (SNELIS) e, sobretudo, à legislação sinalizada e disponibilizada no mesmo espaço. O intuito foi identificar documentos orientadores e normativos direcionados à pessoa com deficiência e que continham pontos específicos que tratavam do lazer e/ou do esporte.

Para apresentar o levantamento realizado e os resultados da pesquisa, este artigo está dividido em três seções. A primeira trata de como a CF e as leis federais legislam sobre o direito da pessoa com deficiência. A segunda cumpre o papel de analisar a legislação que tem como foco as pessoas com deficiência e as políticas de lazer para essas pessoas. Na terceira, por sua vez, são apresentados os resultados do levantamento realizado em relação à cidade de Belo Horizonte e as orientações para a política de esporte e lazer para a pessoa com deficiência.

\section{A Legislação Nacional que Normatiza o Direito ao Esporte e ao Lazer}

No Brasil, o esporte e o lazer ainda são tratados como sinônimos. Em boa parte dos municípios, estados e até mesmo na União, os dois temas não são tratados de forma indissociada e, assim, boa parte das políticas e estruturas são formadas a fim de implementar políticas que englobam o esporte e o lazer em uma só atividade, por isso sempre que se trata de políticas de lazer, as políticas de esporte estão presentes.

Entretanto, ao observar as orientações nacionais para o desenvolvimento do lazer como direito social, não é possível identificar que o esporte também ser tratado como um direito. Santos (2014) salienta que a inclusão do lazer como direito social, na Constituição Federal de 1988 (CF/88), foi um marco legislativo para a expansão dos 
direitos sociais e para a unificação das obrigações do Estado com e para o povo brasileiro.

Em seu Art. $6^{\circ}$, a Constituição Federal deixa claro que o lazer é um direito social. Assim, aos entes federados são atribuídas são obrigações de proporcionar à população o acesso a políticas que efetivem esse direito.

Art. $6^{\circ}$ São direitos sociais a educação, a saúde, a alimentação, o trabalho, a moradia, o transporte, o lazer, a segurança, a previdência social, a proteção à maternidade e à infância, a assistência aos desamparados, na forma desta Constituição (BRASIL, 1988, online).

Não menos importante, a Seção III da CF dispõe sobre o desporto e ancora o esporte na assistência social. Salienta-se que, à primeira vista, somente o lazer é tratado como direito social. Entretanto, é importante frisar que o Artigo 217 coloca que é dever do Estado fomentar a prática esportiva formal e não formal.

Art. 217. É dever do Estado fomentar práticas desportivas formais e não formais, como direito de cada um, observados:

I - a autonomia das entidades desportivas dirigentes e associações, quanto a sua organização e funcionamento;

II - a destinação de recursos públicos para a promoção prioritária do desporto educacional e, em casos específicos, para a do desporto de alto rendimento;

III - o tratamento diferenciado para o desporto profissional e o não profissional;

IV - a proteção e o incentivo às manifestações desportivas de criação nacional.

$\S 1^{\circ} \mathrm{O}$ Poder Judiciário só admitirá ações relativas à disciplina e às competições desportivas após esgotarem-se as instâncias da justiça desportiva, regulada em lei.

$\S 2^{\circ}$ A justiça desportiva terá o prazo máximo de sessenta dias, contados da instauração do processo, para proferir decisão final.

$\S 3^{\circ} \mathrm{O}$ poder público incentivará o lazer, como forma de promoção social (BRASIL, 1988, online).

Araújo et al. (2017) salientam que a prática do esporte ainda não está materializada, distanciando o esporte como prática social integrante do patrimônio cultural da humanidade. Mas que, como marco legal, a CF/1988 determina o dever do Estado de fomentar o esporte como direito do cidadão, admitindo a responsabilidade dos entes federados frente à promoção de políticas públicas nesse sentido. 
Todavia, no parágrafo terceiro do artigo em análise, observa-se a inclusão do lazer, deixando ambiguidades e falhas quanto à definição de quais atividades devem ser desempenhadas para cumprir tal ordenamento. Talvez, neste ponto, surja o problema enunciado no início desta seção: o lazer e o esporte no Brasil são tratados de forma sinônima e indissociada, o que faz com que o lazer seja apresentado de forma fragmentada e, talvez, equivocada, já que ele pode ser abordado de diferentes maneiras e através de uma diversidade de conteúdo, das atividades físico-esportivas ao turismo (BRASIL, 1988).

Essa falta de clareza não está presente somente na $\mathrm{CF} / 88$, mas também na Lei ${ }^{\circ}$ 9.615 de 1998, que instituiu normas gerais sobre desporto, única lei que dispõe e dá orientações acerca do esporte no Brasil. Nessa lei, o desporto é caracterizado a partir de quatro diferentes manifestações: desporto educacional, desporto de participação, desporto de rendimento e desporto de formação.

Art. 3o $\mathrm{O}$ desporto pode ser reconhecido em qualquer das seguintes manifestações:

I - desporto educacional, praticado nos sistemas de ensino e em formas assistemáticas de educação, evitando-se a seletividade, a hipercompetitividade de seus praticantes, com a finalidade de alcançar o desenvolvimento integral do indivíduo e a sua formação para o exercício da cidadania e a prática do lazer;

II - desporto de participação, de modo voluntário, compreendendo as modalidades desportivas praticadas com a finalidade de contribuir para a integração dos praticantes na plenitude da vida social, na promoção da saúde e educação e na preservação do meio ambiente;

III - desporto de rendimento, praticado segundo normas gerais desta Lei e regras de prática desportiva, nacionais e internacionais, com a finalidade de obter resultados e integrar pessoas e comunidades do País e estas com as de outras nações.

IV - desporto de formação, caracterizado pelo fomento e aquisição inicial dos conhecimentos desportivos que garantam competência técnica na intervenção desportiva, com o objetivo de promover o aperfeiçoamento qualitativo e quantitativo da prática desportiva em termos recreativos, competitivos ou de alta competição (BRASIL, 1998, online).

Após a promulgação da Lei Pelé, nome popular da Lei n. 9.615, toda a legislação acerca do esporte e do lazer no Brasil baseou-se nessa lei, que coloca o lazer como meio para a prática de esporte com foco educacional. Entretanto, sabe-se que o 
lazer, assim como as demais práticas esportivas, não pode ser caracterizado e manifestado de um único modo. Neste sentido, as demais manifestações do esporte não poderiam ser caracterizadas como práticas de lazer?

Inevitavelmente, os editais federais para o fomento do esporte e do lazer trazem consigo esses pontos, o lazer como meio de uma política de esporte e não como objetivo central. Infelizmente, o campo do lazer e dos esportes em âmbito nacional está regulamentado somente por essas duas leis, que instituem a obrigação do Estado e definem as formas como esse direito pode ser oferecido a população. Sob essa perspectiva, o campo ainda carece de legislação que deixem mais claras as obrigações, assim como os deveres e responsabilidades dos entes federados em relação à efetivação da política.

De toda forma, a CF/1988 e a Lei n. 9.615/1998 são as duas principais normativas brasileiras quando tratamos de assuntos relacionados ao esporte e ao lazer. Para incentivar o alinhamento das políticas públicas de esporte e lazer para as pessoas com deficiência no país, uma série de decretos e leis foram promulgadas no decorrer dos anos. Essas normativas serão apresentadas a seguir, complementando e criando a linha histórica que foi traçada.

\section{A regulamentação Nacional da Política de Esporte e Lazer voltada para as Pessoas com Deficiência no Brasil}

Como salientado na seção anterior, o campo do esporte e do lazer ainda carece de mudanças e não há de ser diferente quando se trata das políticas para as pessoas com deficiência. Para evidenciar como foram os arranjos realizados para melhor atender as pessoas com deficiência nas políticas de esporte e lazer no Brasil, foi realizado um levantamento das leis que vigoraram e as que atualmente dão orientações para a 
realização de políticas inclusivas no Brasil.

No início do levantamento, foram identificadas três normas constitucionais, uma lei complementar, 40 leis, 14 decretos e quatro portarias direcionadas às pessoas com deficiência, que estavam elencadas na lista da SNELIS. Dos documentos levantados, apenas duas normas constitucionais, seis leis e três decretos continham pontos relacionados ao esporte e ao lazer, sendo que cerca de metade falava sobre a adaptação e a acessibilidade de espaços para a fruição do esporte e/ou lazer. A partir dessa pesquisa documental, elaborou-se uma lista com a legislação federal para o esporte e o lazer das pessoas com deficiência, conforme Quadro 1.

Quadro 1: Legislação federal para o Esporte e o Lazer das pessoas com deficiência.

\begin{tabular}{|c|c|c|c|}
\hline $\begin{array}{c}\text { TIPO DE } \\
\text { LEGISLAÇÃO }\end{array}$ & $\begin{array}{c}\mathrm{N}^{\circ} \mathrm{DA} \\
\text { LEGISLAÇÃO }\end{array}$ & TEMA CENTRAL & TRECHOS ESPECÍFICOS \\
\hline Lei & $7.853 / 1989$ & $\begin{array}{l}\text { Dispõe sobre o apoio às } \\
\text { pessoas portadoras de } \\
\text { deficiência, sua integração } \\
\text { social, sobre a } \\
\text { Coordenadoria Nacional } \\
\text { para Integração da Pessoa } \\
\text { Portadora de Deficiência } \\
\text { (Corde), institui a tutela } \\
\text { jurisdicional de interesses } \\
\text { coletivos ou difusos dessas } \\
\text { pessoas, disciplina a atuação } \\
\text { do Ministério Público, } \\
\text { define crimes, e dá outras } \\
\text { providências (BRASIL, } \\
\text { 1989). }\end{array}$ & $\begin{array}{l}\text { Art. } 2^{\circ} \text { Ao Poder Público e seus } \\
\text { órgãos cabe assegurar às pessoas } \\
\text { portadoras de deficiência o pleno } \\
\text { exercício de seus direitos básicos, } \\
\text { inclusive dos direitos à educação, } \\
\text { à saúde, ao trabalho, ao lazer, à } \\
\text { previdência social, ao amparo à } \\
\text { infância e à maternidade, e de } \\
\text { outros que, decorrentes da } \\
\text { Constituição e das leis, propiciem } \\
\text { seu bem-estar pessoal, social e } \\
\text { econômico. }\end{array}$ \\
\hline Decreto & $3.298 / 1999$ & $\begin{array}{l}\text { Regulamenta a Lei n. } 7.853 \text {, } \\
\text { de } 24 \text { de outubro de } 1989 \text {, } \\
\text { dispõe sobre a Política } \\
\text { Nacional para a Integração } \\
\text { da Pessoa Portadora de } \\
\text { Deficiência, consolida as } \\
\text { normas de proteção, e dá } \\
\text { outras providências } \\
\text { (BRASIL, 1999). }\end{array}$ & $\begin{array}{l}\text { Art. } 11^{\circ} \text { o CONADE fica } \\
\text { responsável } \\
\text { por } \\
\text { acompanhar, planejar e avaliar a } \\
\text { execução das políticas setoriais de } \\
\text { educação, saúde, trabalho, } \\
\text { assistência social, transporte, } \\
\text { cultura, turismo, desporto, lazer, } \\
\text { política urbana e outras relativas à } \\
\text { pessoa portadora de deficiência; }\end{array}$ \\
\hline Lei & $10.098 / 2000$ & $\begin{array}{l}\text { Estabelece normas gerais e } \\
\text { critérios básicos para a } \\
\text { promoção da acessibilidade } \\
\text { das pessoas portadoras de } \\
\text { deficiência ou com } \\
\text { mobilidade reduzida, e dá } \\
\text { outras providências } \\
\text { (BRASIL, 2000). }\end{array}$ & $\begin{array}{l}\text { Parágrafo único. No mínimo } 5 \% \\
\text { (cinco por cento) de cada } \\
\text { brinquedo e equipamento de lazer } \\
\text { existentes nos locais referidos } \\
\text { no caput devem ser adaptados e } \\
\text { identificados, tanto quanto } \\
\text { tecnicamente possível, para } \\
\text { possibilitar sua utilização por } \\
\text { pessoas com deficiência, inclusive }\end{array}$ \\
\hline
\end{tabular}




\begin{tabular}{|c|c|c|c|}
\hline & & & $\begin{array}{l}\text { visual, ou com mobilidade } \\
\text { reduzida (Redação dada pela Lei } \\
\text { n. 13.443, de 2017). }\end{array}$ \\
\hline Decreto & $3.956 / 2001$ & $\begin{array}{l}\text { Promulga a Convenção } \\
\text { Interamericana para a } \\
\text { Eliminação de Todas as } \\
\text { Formas de Discriminação } \\
\text { contra as Pessoas Portadoras } \\
\text { de Deficiência (BRASIL, } \\
\text { 2001). }\end{array}$ & $\begin{array}{l}\text { Artigo III, 1- a) medidas das } \\
\text { autoridades governamentais e/ou } \\
\text { entidades privadas para eliminar } \\
\text { progressivamente a discriminação } \\
\text { e promover a integração na } \\
\text { prestação ou fornecimento de } \\
\text { bens, serviços, instalações, } \\
\text { programas e atividades, tais como } \\
\text { o emprego, o transporte, as } \\
\text { comunicações, a habitação, o } \\
\text { lazer, a educação, o esporte, o } \\
\text { acesso à justiça e aos serviços } \\
\text { policiais e as atividades políticas e } \\
\text { de administração. }\end{array}$ \\
\hline Lei & $11.982 / 2009$ & $\begin{array}{l}\text { Acrescenta parágrafo único } \\
\text { ao art. } 4^{\circ} \text { da Lei n. } 10.098, \\
\text { de } 19 \text { de dezembro de } 2000 \\
\text { (BRASIL, 2009a). }\end{array}$ & $\begin{array}{l}\text { Os parques de diversões, públicos } \\
\text { e privados, devem adaptar, no } \\
\text { mínimo, } 5 \% \text { (cinco por cento) de } \\
\text { cada brinquedo e equipamento e } \\
\text { identificá-lo para possibilitar sua } \\
\text { utilização por pessoas com } \\
\text { deficiência ou com mobilidade } \\
\text { reduzida, tanto quanto } \\
\text { tecnicamente possível. }\end{array}$ \\
\hline $\begin{array}{l}\text { Decreto } \\
\text { Legislativo }\end{array}$ & $186 / 2008$ & $\begin{array}{l}\text { Aprova o texto da } \\
\text { Convenção sobre os Direitos } \\
\text { das Pessoas com Deficiência } \\
\text { (BRASIL, 2009b). } \\
\end{array}$ & $\begin{array}{l}\text { Artigo } 30 \text { - Participação na vida } \\
\text { cultural e em recreação, lazer e } \\
\text { esporte. }\end{array}$ \\
\hline Lei & $12.663 / 2012$ & $\begin{array}{l}\text { Dispõe sobre as medidas } \\
\text { relativas à Copa das } \\
\text { Confederações FIFA 2013, à } \\
\text { Copa do Mundo FIFA 2014 } \\
\text { e à Jornada Mundial da } \\
\text { Juventude - 2013 (BRASIL, } \\
\text { 2012a). }\end{array}$ & $\begin{array}{l}\text { Capítulo } \mathrm{V}, \$ 7^{\circ} \text { Os entes } \\
\text { federados e a FIFA poderão } \\
\text { celebrar acordos para viabilizar o } \\
\text { acesso e a venda de Ingressos em } \\
\text { locais de boa visibilidade para as } \\
\text { pessoas com deficiência e seus } \\
\text { acompanhantes, } \\
\text { assegurado, na forma do } \\
\text { regulamento, pelo menos, } 1 \% \text { (um } \\
\text { por cento) do número de } \\
\text { Ingressos ofertados, excetuados } \\
\text { os acompanhantes, observada a } \\
\text { existência de instalações } \\
\text { adequadas e específicas nos } \\
\text { Locais Oficiais de Competição. } \\
\text { Capítulo VII- } \\
\text { CAMPANHAS SOCIAIS NAS } \\
\text { COMPETIÇÕES - o incentivo } \\
\text { para a prática esportiva das } \\
\text { pessoas com deficiência. }\end{array}$ \\
\hline Lei & $12.764 / 2012$ & $\begin{array}{l}\text { Institui a Política Nacional } \\
\text { de Proteção dos Direitos da } \\
\text { Pessoa com Transtorno do } \\
\text { Espectro Autista (BRASIL, }\end{array}$ & $\begin{array}{l}\text { Art. } 3^{\circ} \text { São direitos da pessoa com } \\
\text { transtorno do espectro autista: I - } \\
\text { a vida digna, a integridade física e } \\
\text { moral, o livre desenvolvimento da }\end{array}$ \\
\hline
\end{tabular}




\begin{tabular}{|c|c|c|c|}
\hline & & 2012b). & $\begin{array}{l}\text { personalidade, a segurança e o } \\
\text { lazer. }\end{array}$ \\
\hline Lei & $12.933 / 2013$ & $\begin{array}{l}\text { Regulamenta a Lei n. } \\
12.852 \text {, de } 5 \text { de agosto de } \\
2013 \text {, e a Lei n. 12.933, de } \\
26 \text { de dezembro de 2013, } \\
\text { para dispor sobre o benefício } \\
\text { da meia-entrada para acesso } \\
\text { a eventos artístico-culturais } \\
\text { e esportivos (BRASIL, } \\
2013 \text { ). }\end{array}$ & $\begin{array}{l}\text { Art. } 1^{\circ} \text { Este Decreto regulamenta } \\
\text { o benefício da meia-entrada para } \\
\text { acesso a eventos artístico- } \\
\text { culturais e esportivos por jovens } \\
\text { de baixa renda, por estudantes e } \\
\text { por pessoas com deficiência. } \\
\text { Art. } 6^{\circ} \text { As pessoas com } \\
\text { deficiência terão direito ao } \\
\text { benefício da meia-entrada. }\end{array}$ \\
\hline Lei & $13.146 / 2015$ & 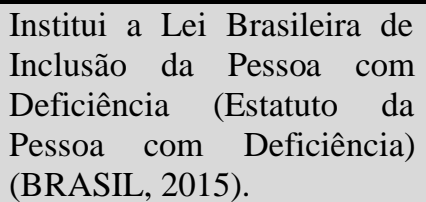 & $\begin{array}{l}\text { Capítulo IX- Do direito à cultura, } \\
\text { ao esporte, ao turismo e ao lazer. }\end{array}$ \\
\hline
\end{tabular}

Fonte: Elaborado pelas autoras.

Dentre os documentos levantados, destacam-se a Lei n. 7.853/1989, o Decreto n.

3.298/1999 e a Lei n.13.146/2015. Entretanto, ressalta-se que, até o desenvolvimento da

Lei Brasileira de Inclusão da pessoa com deficiência, reconhecida popularmente como

Estatuto da Pessoa com Deficiência, em 2015, outras leis abrangeram temas que foram compilados nesse único documento, facilitando o acesso às informações.

A primeira lei, após a promulgação da $\mathrm{CF} / 1988$, que buscou regulamentar os direitos das pessoas com deficiência foi a Lei n. 7.853/1989, que dispôs sobre orientações para o apoio às pessoas portadoras de deficiência e sua integração social, bem como legislou sobre o pleno exercício dos direitos sociais básicos, como a educação, a saúde, o trabalho, o lazer e a previdência social.

Entretanto, ao observar as demais leis, é possível identificar que a Lei n. 7.853/1989 foi regulamentada pelo Decreto n. 3.298/1999, após dez anos da redação da proposta original, o decreto reconheceu a necessidade de elucidar pontos específicos da lei.

Nesse sentido, frisamos que a Lei n. $7.853 / 1989$, em seu artigo $2^{\circ}$, reitera que é dever do Poder Público e seus órgãos assegurar às pessoas com deficiência o pleno 
exercício de seus direitos básicos, como a educação, o lazer, a saúde e demais direitos elencados na $\mathrm{CF} / 1988$. Entretanto, a lei, como forma de orientação às obrigações do poder público e das diferentes esferas de governo, não explicita como os órgãos competentes devem agir de modo a assegurar esses direitos. Esse detalhamento referente às atribuições e responsabilidades do estado vai aparecer no Decreto $\mathrm{n}$. 3.298/1999, que elucida as temáticas abordadas na lei, de forma que cada um dos direitos assinalados na CF/1988 ganha uma seção exclusiva para orientar os serviços do poder público e seus órgãos.

Levando em conta os dois ordenamentos e as diferenças entre os mesmos, cabe esclarecer que as leis têm por fim criar, extinguir ou realizar modificação em direitos e deveres já colocados pela $\mathrm{CF} / 1988$, normativa de maior poder no país. Nesse caso, a lei baseia-se na constituição e o decreto se orienta pela lei, uma vez que os decretos são apenas meio para esclarecimento de pontos colocados nas leis.

Os direitos assinalados no Artigo $2^{\circ}$ da Lei n. 7.853/1989 foram desenvolvidos e elucidados em diferentes seções do Decreto n. 3.298/1999. Na seção V do Decreto n. 3.298/1999 (BRASIL, 1999), estão as orientações para a cultura, desporto, turismo e lazer, em seus artigos $46^{\circ}, 47^{\circ}$ e $48^{\circ}$. Em suma, os artigos dispõem sobre as obrigações dos entes federados quanto a adequação dos espaços e oferta de programas para atenderem as pessoas com deficiência para que possam usufruir das atividades, promovendo a "construção, ampliação, recuperação e adaptação de instalações desportivas e de lazer" (BRASIL, 1999, online).

É importante frisar que o decreto promulgado em 1999 constitui-se como a primeira legislação na qual é possível observar maiores informações sobre como o Estado deve orientar as políticas públicas de esporte e lazer para as pessoas com 
deficiência no Brasil, referindo-se não somente à promoção, mas legislando também sobre o acesso e, principalmente, sobre a acessibilidade (BRASIL, 1999).

Em suma, o Decreto n. 3.298/1999 pode ser considerado como ordenador das demais leis que regulamentam a política de esporte e lazer para as pessoas com deficiência no Brasil, devido à robustez e detalhamento das orientações.

No período entre a publicação da lei e promulgação da Política Nacional para a Integração da Pessoa Portadora de Deficiência, o Decreto n. 3.298/1999, não houve nenhuma outra normativa que tratasse da política para a pessoa com deficiência relacionada ao esporte e ao lazer no Brasil.

Após esses dez anos, a partir dos anos 2000, é possível observar uma ampliação no número de leis que regulamentam o esporte e o lazer para pessoa com deficiência no Brasil. A Lei n. 10.098/2000 e a Lei n. 11.982/2009 dão orientações para a acessibilidade de parques de diversões, públicos e/ou privados, que deverão ter, no mínimo, 5\% de cada brinquedo e equipamento adaptado para uso de pessoas com deficiência (BRASIL, 2000; 2009a). Dessa forma, as pessoas com deficiência passariam a usufruir desses espaços com melhores condições. Tais leis estão em consonância com o Decreto n. 3.956/2001, que orienta a eliminação de barreiras que impossibilitam a integração na prestação de serviços, bens, instalações, programas e demais atividades, como o esporte, a educação, o transporte e demais direitos (BRASIL, 2001).

As políticas públicas, assim como a legislação, são redigidas de modo a resolver problemas de cunho social. No caso da garantia dos direitos das pessoas com deficiência, uma das necessidades é a construção de espaços inclusivos e que possibilitem a troca de experiências e vivências, conforme já sinalizado no Decreto n. 3.956/2001, que promulga a Convenção Interamericana para a Eliminação de Todas as Formas de Discriminação contra as Pessoas Portadoras de Deficiência. 
Nos últimos anos, o Brasil recebeu diversos megaeventos, como a Copa das Confederações - FIFA 2013, a Copa do Mundo - FIFA 2014 e, por fim, um grande evento esportivo, os Jogos Olímpicos e Paralímpicos, em 2016. Todos esses eventos fizeram com que o país investisse em legislação voltada para a acessibilidade do público aos espaços de realização dos eventos. Para melhor atender as pessoas com deficiência, a Lei n. 12.663/2012 dispôs que, no mínimo, 1\% dos ingressos dos espaços oficiais de competição devem ser disponibilizados para as pessoas com deficiência, sendo que esses espaços precisam oferecer instalações adequadas e específicas para o público (BRASIL, 2012b).

Antes da realização dos eventos esportivos, o Brasil aprovou o texto redigido na Convenção de Direitos das Pessoas com Deficiência, realizada em 2008, por meio do Decreto n.6.949/2009 (BRASIL, 2009b) e que, em 2015, aparentemente, tornou-se o Estatuto da Pessoa com Deficiência, pela Lei n. 13.146/2015, que instituiu a Lei Brasileira de Inclusão da Pessoa com Deficiência - Estatuto da Pessoa com Deficiência (BRASIL, 2015).

Ambas as leis são imprescindíveis, quando se trata de direitos para as pessoas com deficiência no esporte e no lazer, pois são os únicos documentos que dão orientações claras sobre o tema, assim como sobre os demais direitos constitucionais (BRASIL, 2009b; 2015).

Tratando-se de esporte e lazer, o Estatuto da Pessoa com Deficiência possui capítulo exclusivo sobre o direito à cultura, ao desporto, ao esporte, ao turismo e ao lazer, tendo como base as demais leis e decretos já existentes na legislação brasileira, como a Lei n. 7.853/1989 (BRASIL, 1989), que instituiu a Coordenadoria Nacional para Integração da Pessoa Portadora de Deficiência (Corde) e apontou a necessidade de leis especificando o direito das pessoas com deficiência e as modificações necessárias 
para que essas pessoas pudessem exercer plenamente os direitos básicos já sinalizados na $\mathrm{CF} / 1988$.

O Estatuto da pessoa com deficiência dá um salto não só por ser um documento que compila as obrigações do Estado para e com as pessoas com deficiência, mas por dar orientações para as políticas públicas de esporte e lazer que, ao contrário dos demais direitos básicos constitucionais, não têm um sistema ou legislação próprios.

O Estatuto da Pessoa com Deficiência regulamenta que o direito à cultura, ao esporte, ao turismo e ao lazer deve ser garantido, com igualdade de oportunidade e de acesso. Para o acesso aos bens mencionados no estatuto, devemos nos atentar à nomenclatura utilizada. Manzini (2005) nos alerta como a nomenclatura pode ser erroneamente usada, esclarecendo que acesso implica o processo para algo, já a acessibilidade pode ser considerada como algo mais concreto e palpável. A Associação Brasileira de Normas Técnicas (ABNT) define acessibilidade, por meio da norma NBR9050, como a

[...] possibilidade e condição de alcance, percepção e entendimento para utilização, com segurança e autonomia, de espaços, mobiliários, equipamentos urbanos, edificações, transportes, informação e comunicação, inclusive seus sistemas e tecnologias, bem como outros serviços e instalações abertos ao público, de uso público ou privado de uso coletivo, tanto na zona urbana como na rural, por pessoa com deficiência ou mobilidade reduzida (ASSOCIAÇÃO BRASILEIRA DE NORMAS TÉCNICAS, 2020, p. 2).

Já acessível é definido como a possibilidade de uso dos "espaços, mobiliários, equipamentos urbanos, edificações, transportes, informação e comunicação, inclusive seus sistemas e tecnologias ou elemento que possa ser alcançado, acionado, utilizado e vivenciado por qualquer pessoa" (ASSOCIAÇÃO BRASILEIRA DE NORMAS TÉCNICAS, 2020, pág. 2). Tendo em consideração essas definições, Manzini (2005) salienta que quatro elementos principais podem ser abstraídos do conceito de acessibilidade, que são: a) edificações; b) transporte; c) equipamentos e mobiliários; e 
d) sistemas de comunicações e, recentemente, as informações, os sistemas e as tecnologias envolvidos para o acesso ao bem mencionado, seja ele público e/ou privado. Por meio da Lei n. 13.146/2015 (BRASIL, 2015) torna-se obrigatório que todos os espaços de cultura, esporte, turismo e lazer devem estar em formato acessível para as pessoas com deficiência, sendo assim, todos os espaços devem possibilitar a fruição plena de todos (BRASIL, 2015; ASSOCIAÇÃO BRASILEIRA DE NORMAS TÉCNICAS, 2020).

$\mathrm{O}$ acesso a estes bens implica, como mencionado acima, mais que a existência de espaços acessíveis, a possibilidade efetiva de usufrui-los. Anterior à Lei n. 13.146/2015, popularizada como Estatuto da pessoa com deficiência, em 2013 por meio da Lei n. 12.933/2013, as pessoas com deficiência, idosos, jovens de baixa renda e estudantes passaram, por exemplo, a ter o direito à meia-entrada em eventos artísticoculturais e esportivos, como forma de popularizar o acesso a esses bens.

Em suma, a legislação analisada neste estudo sinaliza para o atrelamento dos direitos garantidos pela $\mathrm{CF} / 1988$ e a necessidade de ordenamentos legislativos que tragam consigo os direitos e obrigações de cada ente federado. Isso significa dizer que há a necessidade de sintonização entre direitos e deveres para o oferecimento de bens tanto estatais quanto de cunho privado. Acima de tudo, a análise revelou que é preciso que a legislação federal para o esporte e o lazer para as pessoas com deficiência seja mais incisiva e objetiva quanto às obrigações dos diferentes entes federados, pois ela deixa em aberto as atribuições e competências estabelecidas a cada esfera de governo, impedindo que haja clareza sobre de quem deverão ser cobradas as ações.

\section{A Regulamentação Municipal da Política de Esportes e Lazer}

Como já foi mencionado, as orientações para a elaboração de políticas públicas 
são realizadas por meio de ordenamentos legislativos, como leis, decretos, manuais e demais documentos que dispõem sobre direitos e deveres. As leis, decretos e manuais que orientam as políticas públicas de esporte e lazer são comuns, devido à lacuna existente na $\mathrm{CF} / 1988$, soberana e base para as demais orientações.

Para além disso, a inexistência de um sistema de esporte e lazer, assim como um plano de desenvolvimento da área, faz com que cada ente federado e mesmo as iniciativas privadas sigam diretivas próprias e, na maioria das vezes, há certa percepção de que isso se faz de forma frágil no contexto dos governos locais” (MENICUCCI, 2008, p. 180; CARAVAGE e OLIVER, 2018). Vale ressaltar que, num sistema federativo como o brasileiro, o município dispõe de autonomia decisória política e administrativa para formular e implementar suas políticas públicas (CARAVAGE e OLIVEIRA, 2018). Nesse caso, a elaboração da legislação é atribuída à câmara municipal de vereadores, órgão eleito democraticamente para dar prosseguimento às políticas públicas municipais, de modo geral, atentando para os direitos estabelecidos pela constituição federal e demais leis que se sobrepõem às estabelecidas pelo município.

A cidade de Belo Horizonte dispõe de legislação que tem por fim orientar os demais órgãos municipais na elaboração e execução de políticas públicas. Como colocado anteriormente, não há uma orientação clara nacional sobre as atribuições e responsabilidades de cada ente federado em relação à política de esporte e lazer. Entretanto, a inexistência de documento federal não exime o município da realização de políticas de esporte e lazer (BRASIL, 1998).

O município de Belo Horizonte, objeto central deste estudo, possui a Secretaria Municipal de Esportes e Lazer (SMEL), órgão municipal responsável pelo planejamento, organização, avaliação e implementação da política de esporte e lazer. A 
política de esporte e lazer do município está baseada na Lei n. 9.069/2005, que instituiu a política municipal de incentivo ao esporte e ao lazer (BELO HORIZONTE, 2005). Sobre o documento, é possível observar a objetividade com que a temática foi tratada, bem como a orientação para o oferecimento de uma política inclusiva a todos.

$\mathrm{O}$ artigo $5^{\circ}$ da referida lei reitera a importância da democratização da política municipal de esporte e lazer, com a participação de toda comunidade. Destaca necessidade de adaptação dos projetos de instalação esportiva para a pessoa com deficiência. E ressalta como um dos objetivos da política o desenvolvimento de projetos de esporte e lazer que priorize a inclusão social de idosos e pessoas com deficiência (BELO HORIZONTE, 2005).

A partir da Lei n. 9.069/2005 outras leis e decretos foram promulgados e deram demais orientações para a realização de políticas de esportes e lazer no município. Em 2010, foi instituído o Programa Esporte para Todos, por meio do Decreto n. 14.183/2010 (BELO HORIZONTE, 2010), que tem por objetivo realizar parceria com clubes sócio recreativos para a implementação de núcleos esportivos, com módulos de atividades orientados e avaliados pela SMEL. Dessa forma, além dos núcleos implementados pelo município, a cidade dispõe de profissionais e espaços através da realização de parceria público-privada.

Em 2011, instituíram-se os Jogos Escolares de Belo Horizonte (JEBH), evento esportivo de cunho educacional que, além de oferecer modalidades do ciclo olímpico, deve assegurar a inclusão de, no mínimo, uma modalidade coletiva e uma modalidade individual do ciclo de esportes paralímpicos (BELO HORIZONTE, 2011).

Para além de órgãos da administração direta, nesse caso representado pela SMEL, os conselhos têm importante missão na formulação e acompanhamento das políticas públicas. Um importante ordenamento que dá orientações e metas para a 
realização da política de esportes e lazer para a pessoa com deficiência em $\mathrm{BH}$ foi elaborado, recentemente, pelo Conselho Municipal dos Direitos da Pessoa com Deficiência (CMDPD), que se configura como um conselho deliberativo, controlador e fiscalizador da política de atendimento aos deficientes no âmbito do município (BELO HORIZONTE, 1995).

Por meio da Resolução 06/2019a, elaborada pelo CMDPD, formulou-se o Plano de Políticas para as pessoas com deficiência, cuja elaboração contou com a participação de diversos atores, representantes de órgãos públicos e da sociedade civil. Por meio dessa resolução, é possível identificar o histórico da pessoa com deficiência na cidade, acessar dados quantitativos e qualitativos sobre esse público e identificar objetivos e metas traçados para os próximos anos, considerando a implementação de políticas públicas para pessoas com deficiência (BELO HORIZONTE, 2019a).

Cabe salientar que esse plano se destina a esclarecer metas não somente para o esporte e o lazer, objeto central dessa pesquisa, mas contempla o acesso a direitos sociais mais amplos. Dessa forma, o documento dispõe sobre habitação, educação, alimentação, transporte, cultura, saúde, comunicação, emprego e assistência social. Foram traçadas 174 metas, distribuídas em nove eixos diferentes, sendo que, dessas metas, 10 são direcionadas exclusivamente ao esporte e ao lazer. (BELO HORIZONTE, 2019a).

Sobre as metas estabelecidas para o esporte e o lazer, foram elaboradas propostas com prazo permanente, médio e curto. Com relação às metas permanentes, temos a realização bianual da Corrida Rústica, organizada pelo Programa Superar ${ }^{3}$, com o objetivo de realizar evento inclusivo e para pessoas com deficiência na cidade e que,

${ }^{3}$ O Programa Superar é um dos programas implementados pela Prefeitura Municipal de Belo Horizonte MG, criado em 1994 que tem como objetivo oferecer à pessoas com deficiência atividades esportivas e de lazer. Mais informações e especificações sobre o projeto estão detalhadas no Capítulo IV - A implementação das ações de esporte e lazer no município. 
infelizmente, não vem sendo realizado nos últimos anos. Além da Corrida Rústica, temos a Copa Centenário de Futebol Amador e os Jogos Escolares de Belo Horizonte (JEBH), ambos caracterizados como metas permanentes para a viabilização de acesso para as pessoas com deficiência (BELO HORIZONTE, 2019a).

As metas de médio prazo estão relacionadas à ampliação de atendimento no Programa Superar e ao aumento de núcleos e do número de pessoas atendidas. De acordo com o Relatório Demonstrativo da Execução de Metas Físicas, disponibilizado no Portal da Prefeitura de Belo Horizonte, nos anos de 2017 a 2019, houve aumento de atendimento no quesito formação. Salienta-se que o programa possui duas formas de atendimento, formação de profissionais e sociedade civil, nomeada como formação atendimentos, e atendimentos educacionais para as pessoas com deficiência, nomeados como Superar Educacional atendidos (BELO HORIZONTE, 2018; 2019a; 2019b; 2020).

As metas do Plano Municipal para a pessoa com deficiência, no que diz respeito ao esporte e ao lazer, consideradas de curto prazo correspondem à viabilização de parcerias federais para o desenvolvimento de infraestrutura para o formação de atletas de alto rendimento; à ampliação da acessibilidade a equipamentos no formato universal, sinalizado na ABNT 9050:2020, e ao cadastramento de todas as pessoas com deficiência atendidas pelos programas da SMEL, no formato já realizado pelo Programa Superar, seguindo as orientações do Estatuto do Idoso, Lei n. 10.741/03, e da Lei Brasileira de Inclusão, Lei n. 13.146/15 (BELO HORIZONTE, 2019a).

Sobre o monitoramento dos atendimentos e o cadastramento dos atendidos, bem como sobre as individualidades de cada um, este estudo, ao iniciar a busca por informações, já sinalizava para a falta de dados dos atendimentos dos demais programas desenvolvidos pela SMEL. Apenas o Programa Superar, que atende exclusivamente 
pessoas com deficiência, disponibiliza dados sobre quem são as pessoas atendidas e quais atividades são desenvolvidas. Dessa forma, a ampliação de ações voltadas para a avaliação e o monitoramento dos demais programas é imprescindível para realizar futuras alterações na política, visando seu aprimoramento (BELO HORIZONTE, 2019a).

Não menos importante que a resolução 06/2019, elaborada pelo CMDPD, tramita na câmara de vereadores do município o Projeto de Lei n. 367/2017, que dispõe sobre a consolidação municipal referente a acessibilidade, atendimentos referenciais e direitos da pessoa com deficiência. Na proposta, consta ponto específico voltado para o lazer e o esporte, que dispõe, principalmente, sobre a acessibilidade aos espaços públicos e privados, bem como sobre a necessidade de maior financiamento para programas para pessoas com deficiências. Até a divulgação desta pesquisa, o projeto encontrava-se em discussão parlamentar para adequações à proposta original (BELO HORIZONTE, 2017; 2019a).

As metas apresentadas pelo Conselho Municipal da Pessoa com Deficiência (CMDPD/BH) representam importantes passos para que a política desenvolvida na cidade possa ser aprimorada, já que as metas de curto prazo têm como objetivo o mapeamento das necessidades do público atendido. Esse mapeamento é fundamental, devido à carência de dados sobre pessoa com deficiência não só em $\mathrm{BH}$, mas em boa parte dos municípios. Dessa forma, caso o Plano Municipal seja seguido, configura-se como importante ferramenta para a implementação de políticas públicas municipais não só para o esporte e o lazer, mas para as demais pastas que dispõem sobre atendimento à pessoa com deficiência. 


\section{Considerações Finais}

A respeito do arcabouço normativo para as políticas de esporte e lazer para as pessoas com deficiência no Brasil, nota-se a ampliação do aparato legal nacional, que regula e orienta as políticas para o atendimento das pessoas com deficiência nos programas de esporte e lazer. Destaca-se a promulgação do Estatuto da Pessoa com deficiência, que detalhou os direitos ao esporte e ao lazer para esse público, no sentido de regulamentar o direito previsto na Constituição Federal de 1988. Ou seja, a regulamentação da política nacional para as pessoas com deficiência têm sido um parâmetro importante para a implementação de uma perspectiva inclusiva das políticas de esporte e lazer nas diferentes esferas de governo.

Em relação à legislação municipal que trata dos direitos ao esporte e ao lazer para as pessoas com deficiência, tem ocorrido um movimento mais amplo na tentativa de aperfeiçoamento dos programas e ampliação do acesso ao público. A criação do Plano Municipal para pessoas com deficiência, pelo Conselho Municipal para pessoas com deficiência, em 2019, é um exemplo das ações que vêm sendo realizadas no sentido de efetivar uma política mais assertiva para esse público. O plano municipal consiste na elaboração de metas para modificação e ampliação do acesso a políticas públicas para pessoas com deficiência na cidade.

Dessa forma, foi possível identificar no estudo que o Governo Federal, assim como a Prefeitura Municipal de Belo Horizonte - MG, tem legislações pertinentes ao desenvolvimento de políticas de esporte e lazer que atendam as pessoas com deficiência de forma a realizar a inclusão social, entretanto não é possível identificar diretrizes claras de como estas políticas devem ser implementadas. E que as legislações sobre as pessoas com deficiência e seus direitos são as que trazem consigo maiores potenciais de orientação da política de esporte e lazer para as pessoas com deficiência. 


\section{REFERÊNCIAS}

ARAujo, S. M.; ARAUJO, R. A. S.; NUNES, A. S. A.; MOUTINHO, A. M. S.; TEIXEIRA, P. L. O esporte como direito social: notas sobre a legislação esportiva no estado do Maranhão. In: Jornada Internacional de Políticas Públicas: 1917-2017: um século de reforma e revolução, 22 a 25 de agosto. 8, 2017, São Luís. Anais [...] São Luís: Universidade Federal do Maranhão, 2017.

ANDRADE, A. C.; ALMEIDA, M. A. B. de. Análise documental das políticas públicas de incentivo as práticas físico-esportivas e de lazer para as pessoas com deficiência no brasil. Conexões, $[S . \quad$ l. $], \quad$ v. $\quad 10, \quad$ n. $\quad 3, \quad$ p. $42-60, \quad 2012 . \quad$ DOI: 10.20396/conex.v10i3.8637646. Disponível em: https://periodicos.sbu.unicamp.br/ojs/index.php/conexoes/article/view/8637646. Acesso em: 26 out. 2020 .

ASSOCIAÇÃO BRASILEIRA DE NORMAS TÉCNICAS. Acessibilidade a edificações, mobiliário, espaços e equipamentos urbanos. ABNT NBR 9050:2020. Rio de Janeiro, 2020.

BARBOSA, Cláudia Márcia; REZENDE, Edson, José C. e BRITO, Cristiane Miryam D. de. Pessoas com deficiência e o lazer: uma análise das publicações nas revistas brasileiras Licere e RBEL. Revista Brasileira de Estudos do Lazer. v. 7, n. 3, set/dez, p. 123-139, 2020.

BARDIN, Laurence. Análise de conteúdo. São Paulo: Edições 70, 1979.

BELO HORIZONTE. Lei $\mathbf{n}^{\mathbf{0}}$ 6953, de 10 de outubro de 1995. Conselho Municipal Dos Direitos Da Pessoa Com Deficiência e dá outras providências. Belo Horizonte - MG, 1995. Disponível em: https://leismunicipais.com.br/a/mg/b/belo-horizonte/leiordinaria/1995/695/6953/lei-ordinaria-n-6953-1995-cria-o-conselho-municipal-depessoas-portadoras-de-deficiencia-e-da-outras-providencias. Acesso em: 10 out. 2020.

Lei $\mathbf{n}^{\mathbf{0}}$ 9069, de 17 de janeiro de 2005. Institui a política municipal de incentivo ao esporte e ao lazer e dá outras providências. Belo Horizonte, 2005. Disponível em: https://leismunicipais.com.br/a/mg/b/belo-horizonte/lei-ordinaria/2005/907/9069/leiordinaria-n-9069-2005-institui-a-politica-municipal-de-incentivo-ao-esporte-e-ao-lazere-da-outras-providencias. Acesso em: 13 jul. 2019.

Decreto $\mathbf{n}^{\mathbf{0}} \mathbf{1 4 . 1 8 3}$, de 10 de novembro de 2010. Institui o programa esporte para todos, regulamenta o art. 22 da lei $\mathrm{n}^{\circ}$ 9.795/09 e dá outras providências. Belo Horizonte, 2010. Disponível em: https://leismunicipais.com.br/a/mg/b/belohorizonte/decreto/2010/1418/14183/decreto-n14183-2010-institui-o-programa-esporte-para-todos-regulamenta-o-art-22-da-lei-n9795-09-e-da-outras-providencias.

Lei no 10.344, de 21 de dezembro de 2011. Belo Horizonte, MG, 2011. Institui os Jogos Escolares do município de Belo Horizonte - JEBH. Disponível em: https://leismunicipais.com.br/a/mg/b/belo-horizonte/lei-ordinaria/2011/1034/10344/leiordinaria-n-10344-2011-institui-os-jogos-escolares-do-municipio-de-belo-horizontejebh-2011-12-21-versao-compilada. Acesso em: 10 jan. 2020. 
BELO HORIZONTE. Relatório Demonstrativo da Execução das Metas Físicas 2017. 2018. Disponível em: https://prefeitura.pbh.gov.br/sites/default/files/estruturadegoverno/planejamen

to/SUPLOR/Diretoria\%20Centra1\%20de\%20Planejamento/PPAG\%2020142017/Relat\% C3\%B3rios\%20de\%20Monitoramento/demonstrativo_da_execucao_das_metas_fisicas _3_\%C2\%BA_quad_2017\%20(1).pdf. Acesso em: 15 abr. 2019.

. Resolução CRDPD/BH no 06/2019. Plano de políticas para as pessoas com deficiência. 2019a. Disponível em: http://portal6.pbh.gov.br/dom/iniciaEdicao.do?method=DetalheArtigo\&pk=1222165. Acesso em 27 de fev. de 2020.

Relatório Demonstrativo da Execução das Metas Físicas 2018. 2019b. Disponível em: https://prefeitura.pbh.gov.br/transparencia/contas-publicas/planoplurianual-ppag/ppag-2018-2021. Acesso em: 16 fev. 2019.

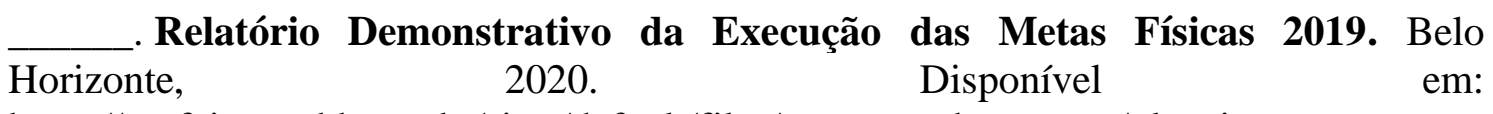
https://prefeitura.pbh.gov.br/sites/default/files/estrutura-degoverno/planejamento /SUPLOR/Diretoria\%20Central\%20de\%20Planejamento/Monitoramento\%202019/Rela t\%C3\%B3rio\%20Demonstrativo\%20da\%20Execu\%C3\%A7\%C3\%A3o\%20metas\%20f isicas\%202019.pdf. Acesso em: 4 jan. 2020.

Projeto de Lei 367. Dispõe sobre a consolidação municipal referente à acessibilidade, atendimentos preferenciais e direitos da pessoa com deficiência da cidade de Belo Horizonte. 2017. Disponível em: https://www.cmbh.mg.gov.br/atividade-legislativa/pesquisar-roposicoes/projeto-delei/367/2017. Acesso em 31 out. 2020.

BRASIL. Constituição da República Federativa do Brasil. Presidência da República; Casa Civíl; Subchefia dos Assuntos Jurídicos. Brasília- DF: 1988. Disponível em: http://www.planalto.gov.br/ccivil_03/constituicao/constituicao.htm. Acesso em: 27 mar. 2020 .

Lei $\mathbf{n}^{0}$ 7.853, de 24 de outubro de 1989. Dispõe sobre o apoio às pessoas portadoras de deficiência, sua integração social, sobre a Coordenadoria Nacional para Integração da Pessoa Portadora de Deficiência - Corde, institui a tutela jurisdicional de interesses coletivos ou difusos dessas pessoas, disciplina a atuação do Ministério Público, define crimes, e dá outras providências. Presidência da República; Casa Civil, Subchefia para Assuntos Jurídicos. Brasília, DF: 1989. Disponível em: http://www.planalto.gov.br/ccivil_03/leis/L7853.htm. Acesso em: 20 jun. 2019.

.Lei no 8.069, de 13 de julho de 1990. Dispõe sobre o Estatuto da Criança e do Adolescente e dá outras providências, Brasília, 1990. Disponível em: http://www.planalto.gov.br/ccivil_03/LEIS/L8069.htm. Acesso em: 04 Abr. 2019.

Lei $\mathbf{n}^{\mathbf{0}} \mathbf{8 . 8 4 2}$, de 4 de janeiro de 1994. Dispõe sobre a política nacional do idoso, cria o Conselho Nacional do Idoso e dá outras providências, 1994. Disponível em: http://www.planalto.gov.br/ccivil_03/leis/L8842.htm. Acesso em: 04 Abr. 2019. 
BRASIL. Lei 9.615, de 24 de março de 1998. Institui normas gerais sobre desporto e dá outras providências. Presidência da república; Casa Civíl; Subchefia dos Assuntos Jurídicos. Brasília- $\quad$ DF: $1998 . \quad$ Disponível em: http://www.planalto.gov.br/ccivil_03/leis/19615compilada.htm. Acesso em: 28 de mar. de 2020.

Decreto $\mathrm{n}^{\circ}$ 3.298, de 20 de dezembro de 1999. Regulamenta a Lei no 7.853, de 24 de outubro de 1989, dispõe sobre a Política Nacional para a Integração da Pessoa Portadora de Deficiência, consolida as normas de proteção, e dá outras providências., 1999. Disponível em: http://www.planalto.gov.br/ccivil_03/decreto/D3298.htm. Acesso em: 04 Abr. 2019.

Lei $\mathrm{n}^{0}$ 10.098, de 19 de dezembro de 2000. Estabelece normas gerais e critérios básicos para a promoção da acessibilidade das pessoas portadoras de deficiência ou com mobilidade reduzida, e dá outras providências. Brasília - DF, 2000. Disponível em: http://www.planalto.gov.br/ccivil_03/LEIS/L10098.htm. Acesso em: 11 de fev. de 2020.

Decreto $n^{0}$ 3.956, de 8 de outubro de 2001.Promulga a Convenção Interamericana para a Eliminação de Todas as Formas de Discriminação contra as Pessoas Portadoras de Deficiência. 2001. Disponível em: http://www.planalto.gov.br/ccivil_03/decreto/2001/D3956.htm. Acesso em: 20 jun. 2019.

Decreto Legislativo n. 186, de 2008. Aprova o texto da Convenção sobre os Direitos das Pessoas com Deficiência e de seu Protocolo Facultativo, assinados em Nova Iorque, em 30 de março de 2007. Senado Federal, Brasília - DF, 2008. Disponível em: http://www.planalto.gov.br/ccivil_03/CONGRESSO/DLG/DLG-186-2008.htm. Acesso em: 06 fev. 2021.

Lei $\mathbf{N}^{\mathbf{1 1}} \mathbf{1 1 . 9 8 2}$, de 16 de julho de 2009. Acrescenta parágrafo único ao art. $4^{\circ}$ da Lei no 10.098 , de 19 de dezembro de 2000, para determinar a adaptação de parte dos brinquedos e equipamentos dos parques de diversões às necessidades das pessoas com deficiência ou com mobilidade reduzida. 2009a. Disponível em: http://www.planalto.gov.br/ccivil_03/_Ato20072010/2009/Lei/L11982.htm. Acesso em: 20 jun. 2019.

Lei $\mathbf{n}^{\mathbf{0}}$ 12.663, de 5 de junho de 2012. Dispõe sobre as medidas relativas à Copa das Confederações FIFA 2013, à Copa do Mundo FIFA 2014 e à Jornada Mundial da Juventude - 2013, que serão realizadas no Brasil; altera as Leis ${ }^{\circ}$ s 6.815 , de 19 de agosto de 1980, e 10.671, de 15 de maio de 2003; e estabelece concessão de prêmio e de auxílio especial mensal aos jogadores das seleções campeãs do mundo em 1958, 1962 e 1970. 2012a. Disponível em: http://www.planalto.gov.br/ccivil_03/_ato20112014/2012/Lei/L12663.htm\#: :text=Disp $\% \mathrm{C} 3 \%$ B5e\%20sobre\%20as\%20medidas\%20relativas, de\%20aux\%C3\%ADlio\%20espec ial\%20mensal\%20aos. Acesso em: 20 jun. 2019.

BRASIL. Lei no 12.764, de 27 de dezembro de 2012. Institui a Política Nacional de Proteção dos Direitos da Pessoa com Transtorno do Espectro Autista; e altera o $\S 3^{\circ}$ do art. 98 da Lei ${ }^{\circ}$ 8.112, de 11 de dezembro de 1990. 2012b. Disponível em: http://www.planalto.gov.br/ccivil_03/_ato2011- 
2014/2012/lei/112764.htm. Acesso em: 20 jun. 2019.

Lei $\mathbf{n}^{\mathbf{0}}$ 12.933, de 26 de dezembro de 2013. Dispõe sobre o benefício do pagamento de meia-entrada para estudantes, idosos, pessoas com deficiência e jovens de 15 a 29 anos comprovadamente carentes em espetáculos artístico-culturais e esportivos, e revoga a Medida Provisória $n^{\circ}$ 2.208, de 17 de agosto de 2001. Presidência da República; Casa Civil; Subchefia para Assuntos Jurídicos. Brasília, DF: 2013. Disponível em: http://www.planalto.gov.br/ccivil_03/_ato20112014/2013/lei/112933.htm. Acesso em: 20 jun. 2019.

Lei $\mathbf{n}^{\circ}$ 13.146, de 6 de julho de 2015. Institui a Lei Brasileira de Inclusão da Pessoa com Deficiência (Estatuto da Pessoa com Deficiência).Presidência da República; Casa Civil; Subchefia para Assuntos Jurídicos. Brasília, DF: 2015. Disponível em: http://www.planalto.gov.br/ccivil_03/_ato2015-2018/2015/lei/113146.htm. Acesso em: 20 jun. 2019.

Protocolo Facultativo à Convenção sobre os Direitos das Pessoas com Deficiência: Decreto Legislativo $n^{\circ} 186$, de 09 de julho de 2008: Decreto $n^{\circ} 6.949$, de 25 de agosto de 2009b. 4. ed. Brasília: Secretaria de Direitos Humanos, 2009b. Disponível em: http://www.planalto.gov.br/ccivil_03/_ato20072010/2009/decreto/d6949.htm. Acesso em: 26 out. 2020.

CARAVAGE, Andressa; OLIVER, Fátima Corrêa; Políticas públicas de esporte e lazer para pessoas com deficiência. Movimento, Julho-setembro 2018, Vol. 24(3), pág. 9871000. Disponível em: https://seer.ufrgs.br/Movimento/article/view/73957/50409. Acesso em: 29 out. 2020.

IBGE. Censo Demográfico - 2010: características da população e dos domicílios. Resultados do universo. Rio de Janeiro: IBGE, 2011.

MANZINI, E. J. Inclusão e Acessibilidade. Revista da Sobama, v. 10, n. 1, p. 31-36, 2005.

MAY, T. Social Research: issues, methods and research. Buckingham [England]: Open University Press, 1993.

MENICCUCI, Telma. Políticas de esporte e de lazer: o estado da arte de um objeto em construção. In: ISAYAMA, Hélder Ferreira; LINHALES, Meyli Assbú (org.). Avaliação de políticas públicas e políticas de avaliação: questões para o esporte e o lazer. Belo Horizonte: Editora UFMG, 2008.

NOYA, Luciana; GOMES, Christianne Luce. O direito ao lazer nas políticas públicas das capitais dos países andinos. Belo Horizonte: Utopika Editorial, 2019.

SANTOS, F. D. C. O lazer como direito social: sua inclusão na Constituição de 1988. São Paulo: Annalume, 2014.

SILVA, J. V. P. da; MENDONÇA, T. C. F. de; SAMPAIO, T. M. V. Grupos de Pesquisas e Enfoque dado ao Lazer das Pessoas com Deficiência na Produção Científica no Brasil. Licere, [S. l.], v. 17, n. 3, p. 66-98, 2014. DOI: http://doi.org/10.35699/19813171.2014.973. Acesso em: 26 out. 2020. 


\section{Endereço das Autoras:}

Débora da Silva Oliveira

Universidade Federal de Minas Gerais - UFMG

Avenida Presidente Antônio Carlos, 6627 - Pampulha

Belo Horizonte - MG - 31.270-901

Endereço Eletrônico: deboraoliveira.edfis@ outlook.com

Luciana Assis Costa

Universidade Federal de Minas Gerais - UFMG

Avenida Presidente Antônio Carlos, 6627 - Pampulha

Belo Horizonte - MG - 31.270-901

Endereço Eletrônico: lucianaassis.ufmg@gmail.com 